\title{
FROM INDIVIDUAL GRAPHITE ASSIGNMENT TO AN IMPROVED DIGITAL IMAGE ANALYSIS OF DUCTILE IRON
}

\author{
J. Friess $(1)$ and A. Bührig-Polaczek \\ Foundry Institute of RWTH Aachen University, Aachen, Germany \\ U. Sonntag \\ GFaI - Society for the Advancement of Applied Computer Science, Berlin, Germany \\ I. Steller \\ BDG - German Foundry Association, Düsseldorf, Germany
}

Copyright (c) 2020 The Author(s)

https://doi.org/10.1007/s40962-020-00416-3

\begin{abstract}
Since graphite classification by visual analysis exhibits large variations, a more integrative concept of graphite shape classification is required to evaluate the correlations of process, microstructure and properties, and to fulfill customers' requirements. The automatic digital image analysis is partly based on visual analysis, but it is not thoroughly defined for graphite shape classification. For example, nodules and thereby nodularity are only defined by the shape parameter roundness, although several studies suggest more sophisticated approaches. Within the first

shape parameters showing that roundness and the assigned minimum limit value of 0.6 are not sufficient to distinguish nodules from less ideal graphite particle shapes. Furthermore, the current classification approach does not represent the full spectrum of graphite morphologies and needs to be extended. The development of a universal hierarchical classification method for nodules and other graphite shapes has been initiated, and the results will contribute to an improved image analysis standard for ductile iron, particularly ISO 945-4.
\end{abstract} of three successive round robin tests, visual assignment for a variety of graphite particles was performed to obtain a universal digital data set of classified graphite particles. For this, the classification approach from standard EN ISO 945-1 was used and extended with degenerated graphite. The assigned particles were evaluated concerning different
Keywords: graphite morphology, graphite classification, nodularity, image analysis, ductile iron, spheroidal graphite cast iron

\section{Introduction}

Increasing demands on cast products are usually accompanied by increasing demands on the material properties. The quantitative description of the microstructure achieved in the product is of high importance, for example the extent of defects or the size and morphology of individual phases. In the course of the increasing digitization of the microstructure description, however, it becomes apparent

This paper is an invited submission to IJMC selected from presentations at the 6th Keith Millis on Ductile Iron held October 23-26, 2018, at the Sonesta Resort, Hilton Head Island, SC. It is published in the IJMC by permission of the DIS (Ductile Iron Society). that the evaluation of geometrically complex structures, such as various types of graphite in cast iron, represents a challenge.

The analysis and description of the graphite morphology in ductile cast iron specifically include graphite content, nodule count, particles sizes, form classification and nodularity. The latter describes the fraction of those particles, which are in the appropriate and acceptable nodule form. ${ }^{1}$ Nodularity values of at least $80 \%$ or $80-85 \%$ are considered acceptable, ${ }^{1,2}$ which is why these values play a crucial role in the quality control. 
Since the visual analysis of graphite phases in cast iron exhibits major variations ${ }^{3,4}$ due to its subjective character, digital image analysis is considered as a suitable, objective and reproducible measuring tool. ${ }^{5}$ So far, different studies have shown that digital image analysis does not yet yield consistent results, ${ }^{4,6}$ thus requiring reliable standards ${ }^{4}$ like ISO 945-4 being developed currently. ${ }^{7}$

It was the aim of the interlaboratory study presented in this paper to achieve a uniform and objective visual assignment for graphite particles, which is not based on the subjective assessment of an individual, but rather on the collective assessment by a representative group of experts. With this uniform set of assigned graphite particles, classification approaches were to be reviewed and evaluated.

\section{Graphite Analysis}

\section{Visual Analysis: State of the Art}

For decades, graphite shapes in cast iron have been evaluated by comparing microscopic images to stylized reference images, both at a preferred magnification of $100 \times$. Two different graphite classification approaches have been standardized by ISO and ASTM (cf. Figure 1), ${ }^{8,9}$ which differ in number, name and portrayed example particles. Nevertheless, both approaches arrange the graphite shape from lamellar toward nodular with some more or less degenerated shapes in between. For example, the defined EN ISO 945-1 shapes $\mathrm{VI}_{\text {ISO }}$ and $\mathrm{V}_{\text {ISO }}$ can be considered similar to ASTM shapes $\mathrm{I}_{\mathrm{ASTM}}$ and $\mathrm{II}_{\mathrm{ASTM}}$, although $\mathrm{II}_{\mathrm{ASTM}}$ presents convex particles, while shape $\mathrm{V}_{\text {ISO }}$ seems more asterisk shaped. They both present desired round particles as well as less round particles, which will probably not impact the mechanical properties. Shapes $\mathrm{IV}_{\text {ISO }}$ and $\mathrm{III}_{\mathrm{ASTM}}$ both present particles which are common in malleable cast iron, but the presented shapes are different. Shapes III $_{\text {ISO }}$ and IV $_{\text {ASTM }}$ represent compacted particles, which are desired for compacted graphite iron and may also occur in spheroidal cast iron. Shape $\mathrm{II}_{\mathrm{ISO}}$ represents a stylized image of degenerated graphite particles known as spiky or intercellular graphite which is mainly caused by trace elements. In contrast to its stylistic depiction, this shape does not appear independently, but only in combination with nodular or lamellar graphite. In contrast, shape $\mathrm{V}_{\text {ASTM }}$ presents a real microscopic image of degenerated graphite, whose appearance differs greatly from $\mathrm{II}_{\mathrm{ISO}}$. While shape $\mathrm{VI}_{\mathrm{ASTM}}$ shows an example of exploded graphite, EN ISO 945-1 does not provide reference pictures for these kinds of graphite degeneration. Both ASTM A247 and EN ISO 945-1 present lamellar graphite ( $\mathrm{I}_{\mathrm{ISO}}$ and $\mathrm{VII}_{\mathrm{ASTM}}$ ) in a similar manner. Next to the stylistic images, EN ISO 945-1 also contains real microscopic example of shapes $\mathrm{I}_{\mathrm{ISO}}$ and $\mathrm{III}_{\mathrm{ISO}}-\mathrm{VI}_{\mathrm{ISO}}$. Within this study, the nomenclature of EN ISO 945-1 is used. For the determination of nodularity, which is the fraction of round graphite particles, references images with nodularities ranging from 50 to $100 \%$ in steps of $5 \%$ can be used.

\section{Digital Analysis: State of the Art}

Since the development of affordable computer technology, digital image analysis has been well established in modern materialography or biological microscopy and thus provides a valid research tool and quality control method. Digital image analysis is applied in an increasing number of iron foundries, but some main issues are still to be solved:

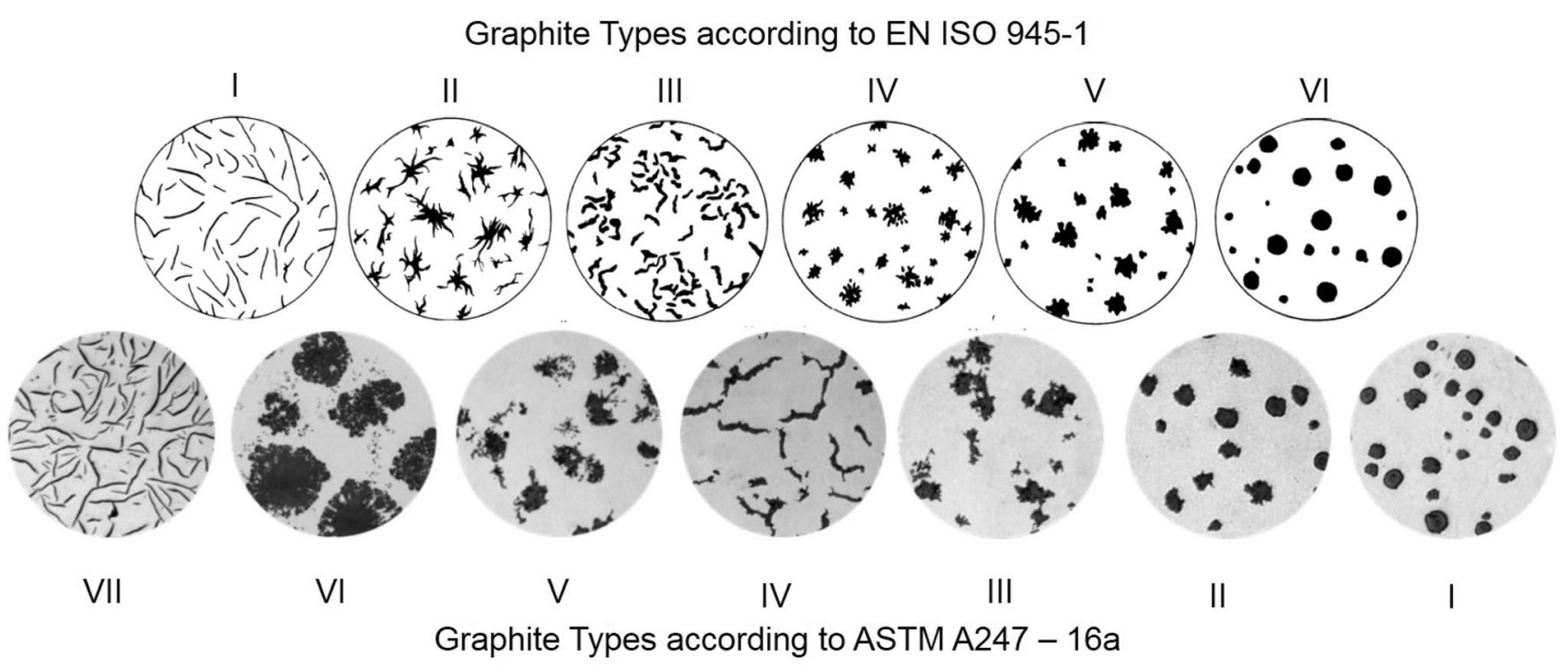

Figure 1. Different standard graphite classification approaches: top row: graphite types according to EN ISO $945-1,{ }^{8}$ bottom row: graphite types according to ASTM A247 - 16a. ${ }^{9}$ 


\section{Algorithm for Digital Analysis in Contrast to Visual Analysis}

Although digital analysis is considered as being equivalent or superior to visual analysis, ${ }^{5}$ the significant difference in the analyzing procedure makes it difficult to compare these two approaches: The human brain is capable of pattern detection and recognition, so it compares the given metallographic image with references images in total and estimates similar particles accordingly. Digital analysis, on the other hand, is based on a precisely defined algorithm that must be implemented in the analyzing software. For image analysis, this is achieved by measuring each individual particle and examining it for predetermined characteristics.

This procedure differs from visual analysis where an integrative comparison is performed. Since it is hard to teach a computer human thinking and automated pattern detection, a clear definition of a round, vermicular, lamellar or in any way degenerated particle is necessary in order to guarantee a reproducible classification. So far, in common regulations a single shape parameter is proposed for shape evaluation. But the shape parameter roundness (cf. F.1), for example, only describes the ratio of the area to the circumscribed circle diameter (FeretMax). Hence, particles with different shapes but the same ratio of area and MaxFeret have the same roundness (cf. Figure 2). The shape is thus only indirectly described by this parameter.

\section{- $\quad$ Roundness $=4 \cdot \operatorname{Area} /\left(\pi \cdot\right.$ MaxFeret $\left.^{2}\right)(F .1)$}

Different suggestions using one or-in a more sophisticated manner-several shape parameters for form evaluation include, for example

- $\quad$ ASTM E2567 - $16 \mathrm{a}^{10}$ : By means of the shape parameter roundness, nodules are described by a minimum value of 0.6 , with the remark that this value can be negotiated between manufacturer and purchaser.

- ISO/DIS 945-4 working $\mathrm{draft}^{7}$ : Aiming at automatical evaluation of nodularity in spheroidal graphite cast iron, graphite particles are assigned to shape $\mathrm{V}_{\text {ISO }}$ or $\mathrm{VI}_{\text {ISO }}$ by setting the roundness ranges between "0.6-0.8" and "0.8-1," respectively. Both ASTM E2567 and ISO 945-4 are striving for nodularity, and a full graphite classification with the help of this shape parameter is not given.

- ISO $16112^{11}$ : standard for compacted graphite iron: Referring to the shape classes of ISO 945-1, the informative appendix suggests graphite particles to be divided into "nodular," "intermediate" and "compacted" with roundness ranges of "0.625-1," "0.525-0.625" and "0-0.525," respectively, neglecting a differentiation between compacted, lamellar and other degenerated particles.

- Velichko ${ }^{12}$ proposed using the two parameters roundness and compactness with different limits according to the graphite size class. This method was not suitable for distinguishing $\mathrm{IV}_{\mathrm{ISO}}$ and $\mathrm{V}_{\text {ISO }}$.

- Shirani and Härkegård ${ }^{13}$ used sphericity and aspect ratio for shape classification according to EN ISO 945-1.

Next to the graphite classification, different formulas for nodularity are used (cf. Table 1).

Accordingly, many attempts have been made in order to provide a unified algorithm for graphite classification and nodularity determination, but no proposal fulfilled all requirements and thus none of them has been adopted globally yet. Thus, image analysis software is using different approaches with partly inaccessible individual settings.

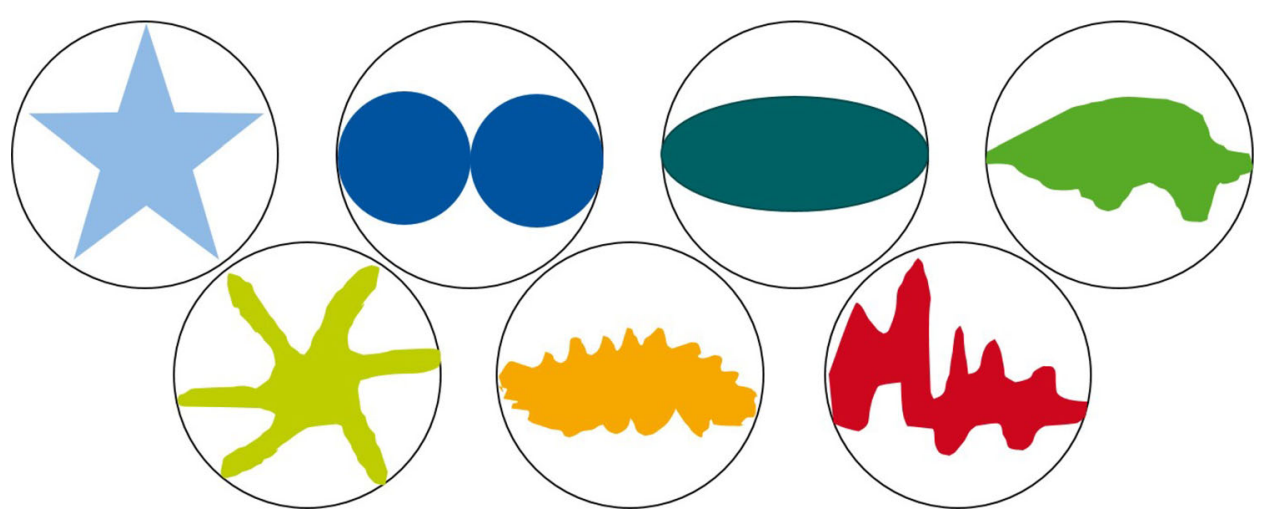

Figure 2. Different shapes can have the same area and MaxFeret (indicated by the circumscribed circle) thus also having the same roundness. 
Table 1. Different Nodularity Formulas (A Area, N Number of Graphite Particles) with Related Roundness Ranges and Minimum Particles Sizes ${ }^{7,14}$

\begin{tabular}{|c|c|c|}
\hline Standard & Nodularity formula & Minimum particle size $(\mu \mathrm{m})$ \\
\hline GB/T 9441-1988 & $\underline{\sum \sum N_{0.8-1}+0.8 \cdot \sum N_{0.6-0.8}+0.6 \cdot \sum N_{0.4-0.6}+0.3 \cdot \sum N_{0.2-0.4}}$ & 20 \\
\hline ASTM E2567 & $\frac{\sum A_{V_{I}+V_{(0.6-1)}}}{\sum A_{1}=1}$ & 10 \\
\hline ISO 16112 & 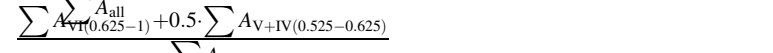 & 10 \\
\hline JIS G5505 & 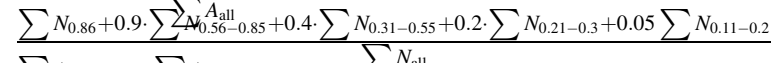 & 10 \\
\hline ISO 945-4 WD & $\frac{\sum A_{\mathrm{VI}(0.8-1)}+\sum A_{\mathrm{V}(0.6-0.8)}}{\sum A_{\text {all }}}$ & 10 \\
\hline
\end{tabular}

\section{Subjective Visual Analysis as a Basis}

Since visual analysis is performed by visual comparison, it is very susceptible to subjective variations. This is caused by different factors including experience, skills and expected result, which leads to different people evaluating the shape and nodularity differently. Furthermore, the compilation of the evaluating images and graphite particles can influence the decision making. An illustrative example might be the Ebbinghaus illusion, where a central circle is perceived in different sizes depending on the size of a ring made up of other circles around it. A similar effect could be considered when evaluating the shape of a graphite particle on the edge between "nodule" and "non-round particle" in between more than a hundred round or non-round particles, respectively, which makes the visual analysis not reproducible.

In order to write an algorithm for graphite classification and nodularity itself as mentioned in the paragraph above, it is first of all necessary to establish a uniform consensus of the individual assignment of graphite particles. This means that, for a multitude of particles, form classification has to be unambiguous. Considering the reference images (cf. Figure 1), an obvious gap and no clear threshold between $\mathrm{V}_{\text {ISO }}$ and $\mathrm{VI}_{\text {ISO }}$ exist. Additionally, the reference image $\mathrm{II}_{\mathrm{ASTM}}$ contains particles which are very round and comparable to the nodules presented in $\mathrm{I}_{\mathrm{ASTM}}$. Furthermore, these simple reference images might not reflect the portfolio of graphite morphologies in spheroidal cast iron.

\section{General Procedure}

Next to different classification algorithms and nodularity formulas, there are more potential causes for scatter during digital image analysis of graphite. This includes different aspects during sample preparation, image acquisition (e.g., exposure, sample position, camera resolution, number of images or particles), image processing (e.g., binarization, noise reduction, edge particles) and measurement itself. In order to guarantee a reproducible image analysis of graphite in cast iron, all of these aspects with their influencing parameter have to be evaluated and understood. Within this study, these aspects were considered by only using images of the same kind to investigate visual and digital classification procedure only.

\section{Design of Experiments}

\section{Industrial Reference Samples}

In order to cover the variety of different graphite morphologies in ductile iron, the industrial project partners of this funded German research and development project were asked to provide metallographic samples with desired and degenerate graphite shapes. A total of eight project partners provided a total of approx. 100 samples. First, these samples were briefly examined. In addition, castings of the materials EN-GJS-400-15 and EN-GJS-500-14 as well as a selection of samples from current and completed public research projects at the Foundry Institute of RWTH Aachen University, Germany, were used to complete the variety of graphite phenomena. Thereupon 50 representative samples were selected under the criteria "nodularity," "graphite size," "graphite number," "vermicular graphite as undesired form in GJS" and "unclassified graphite forms (chunky graphite, etc.)." Malleable cast iron samples (graphite shape $\mathrm{IV}_{\mathrm{ISO}}$ ) could not be used during the round robin test itself due to subsequent delivery by the industry, but were used for evaluation afterward. Figure 3 provides an extract of the selected samples with various graphite morphologies in ductile iron.

\section{Sample Preparation and Image Acquisition}

The embedded metallographic samples were automatically ground with $\mathrm{SiC}$ sandpaper with different grits $(180,320$, 500 and 1000) and polished with diamond polish (size 9, 3 and $0.25 \mu \mathrm{m}$ ). Image acquisition was performed with digital light microscope AxioScope.A1 of Zeiss. Shading correction and light modus " $3200 \mathrm{~K}$ " were applied in order to guarantee homogeneous exposure and consistent contrast. Five images were taken randomly in the middle of the sample at $100 \times$ magnification and at high resolution of $2600 \times 2060$ Pixel with the resulting resolution factor of $0.53 \mu \mathrm{m} /$ Pixel. In the case of very small or very big 

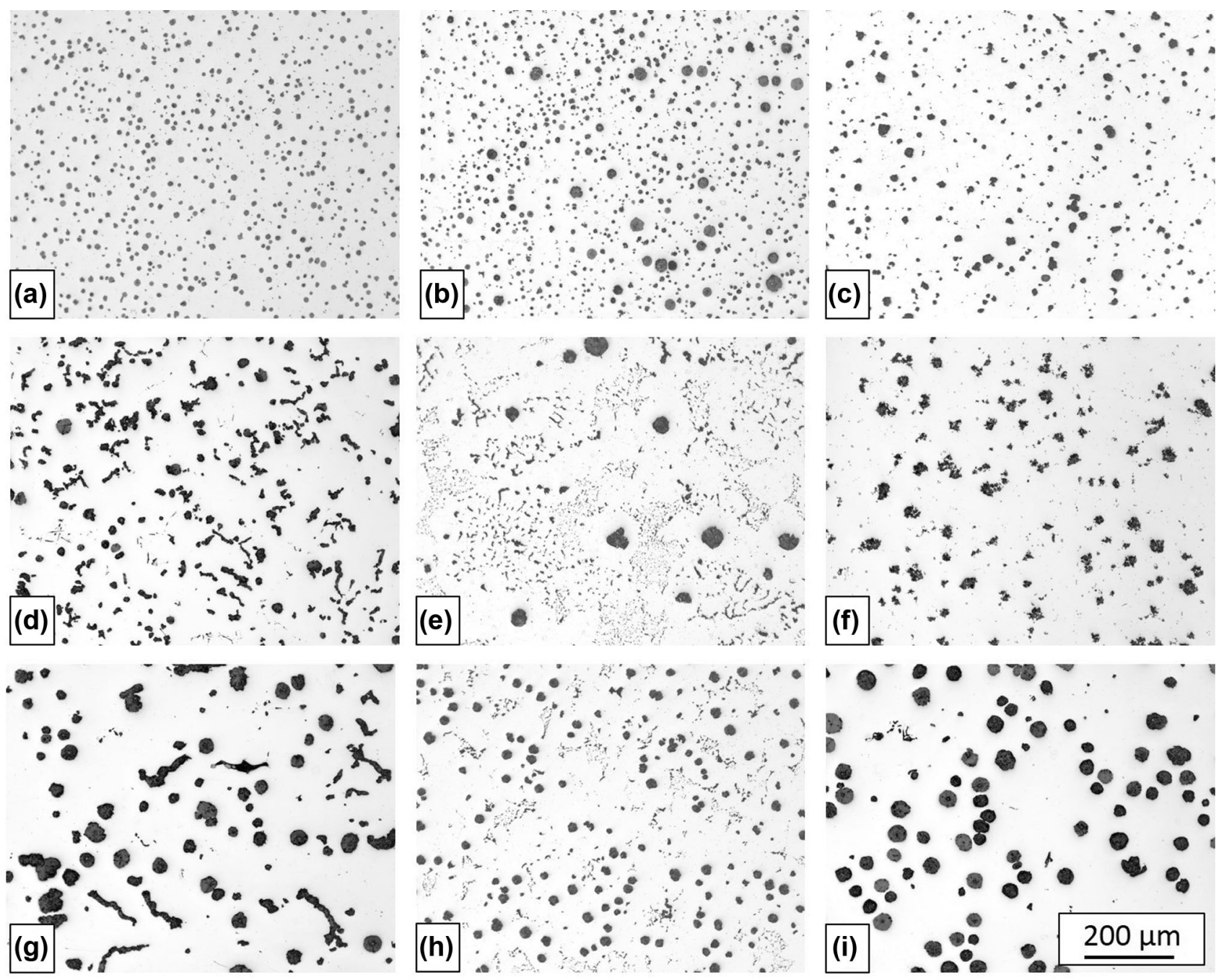

Figure 3. Microscopic images of various industrial and laboratory ductile iron samples with different desired and undesired graphite morphologies in various graphite sizes.

particles, magnification of $200 \times$ or $50 \times$ was additionally chosen. Images were saved in the Zeiss format "zvi" (separate layers and metadata) and converted to jpeg for system-independent handling.

\section{Set-Up of Online Round Robin Test}

The aim of this first interlaboratory study was to create a uniform visual assignment of individual graphite particles and thus to generate an objective data set based on the averaging or totality of individual assignments. For this purpose, the participants should assign a large number of different graphite particles to the form classes of EN ISO 945-1, to graphite degenerations or to "non graphite object." This was realized with an online questionnaire by SoSci Survey. ${ }^{15}$ In particular, both shapes and graphite areas should be assigned and described. In total, 52 images were chosen for testing with 426 marked objects as well as 34 marked graphite areas (cf. Figure 4). The objects were not shown individually, but in context of the microscopic image with neighboring particles. In addition, the nodularity ("total roundness of all particles of an image") should be estimated for 49 images. The task was to follow the EN ISO 945-1 for the visual classification of graphite types since the premise was to build up an automatic classification based on the well-established procedure described in this standard.

Next to visual inspection of different graphite morphologies, additional questions concerning experiences of the participants were imbedded in the round robin test as well as demands and system requirements concerning graphite analysis.

\section{Execution of Round Robin Test}

The access link to the round robin test was distributed among the industrial partner of the corresponding research project as well as to the members of the working group "Quantitative Structural Analysis" of the expert committee 


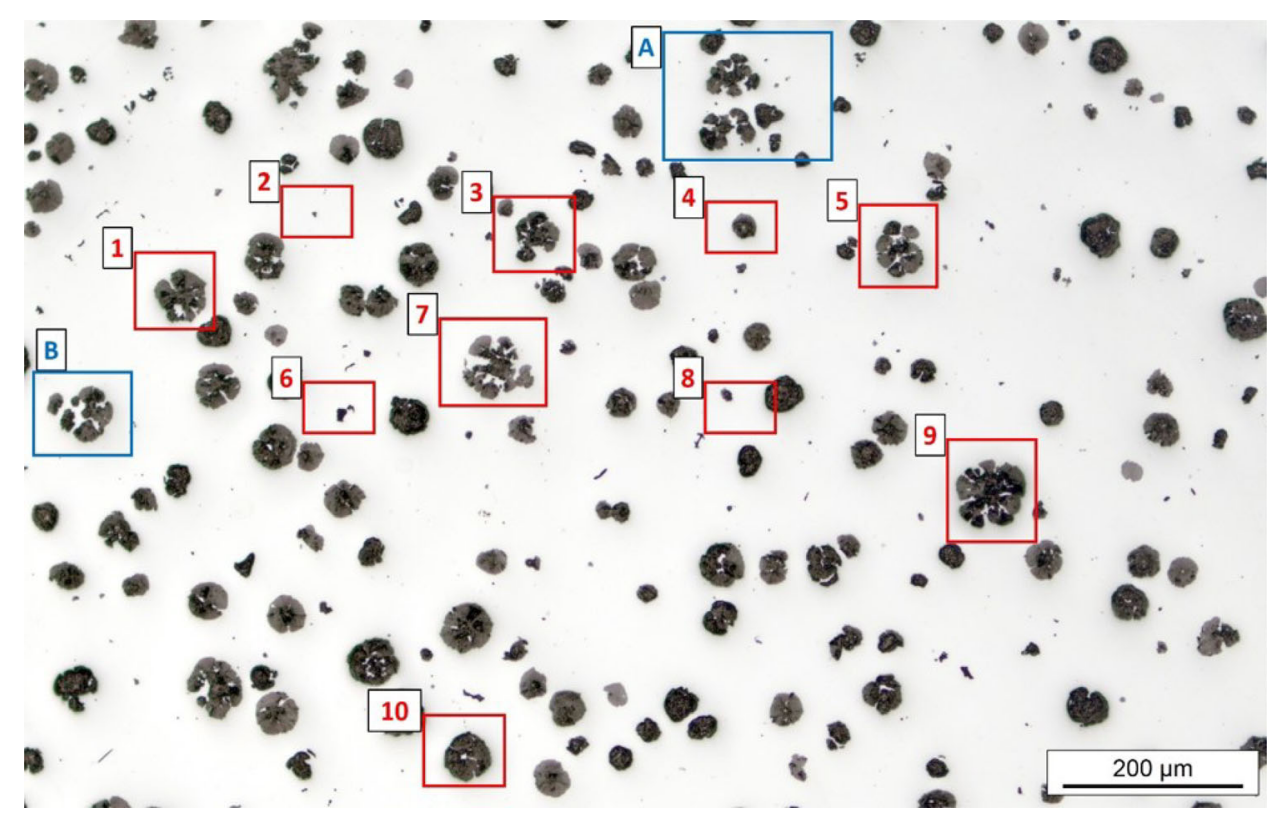

Figure 4. Example image of the round robin test with red marked graphite objects and blue marked graphite areas.

"Materialography" of the "Deutsche Gesellschaft für Materialkunde e.V. (DGM)," thus including cast iron specialists from foundries and customers, experienced metallographers and image analysis programmers. Thirtynine complete and 12 partially completed data sets were collected within the time frame from June until August 2017.

\section{Evaluation Procedure}

Digital graphite particle analysis was performed with the commercial software Zeiss AxioVision version 4.8.

Automatic threshold was applied to binarize the image, and a minimum of 10 pixels was chosen to separate graphite phase from noise. Following characteristics were measured for each particle:

- Area, filled particle area and convex area

- Perimeter, filled particle perimeter and convex perimeter

- FeretMin and FeretMax

- $x$ - and $y$-centroid position

Out of these, the following shape parameters were calculated:

- $\quad$ Roundness (cf. (F.1))

- Compactness $=4 \cdot \pi \cdot$ Area $/(\text { Convex Perimeter })^{2}$ (F.2)

- $\quad$ Feret Ratio $=$ FeretMin/FeretMax (F.3)

- $\quad$ Solidity $=$ Area/Convex Area (F.4)

- Convex Perimeter/Perimeter or Convexity = (Convex Perimeter/Perimeter) $^{2}$ (F.5 and F.6)
- $\quad$ Sphericity $=4 \cdot \pi \cdot$ Area Perimeter $^{2}(\mathrm{~F} .7)$

Furthermore, shape parameters like eccentricity or mean curvature had been considered as well, but were not realized due to additional special implementation. For further analysis and graphite classification, a minimum graphite particles size of 20 pixels $(10.6 \mu \mathrm{m})$ was chosen. For nodularity determination, area fraction of particles with roundness above the threshold value of 0.6 (thus representing $\mathrm{V}_{\text {ISO }}$ and $\mathrm{VI}_{\mathrm{ISO}}{ }^{7}$ ) was calculated $\left(\mathrm{cf.}^{10}\right)$.

\section{Results}

\section{Experiences of and Requests for Graphite Evaluation}

\section{Visual Evaluation of Graphite Morphologies}

Among the participants, considering persons individually as well as companies, $60 \%$ regularly perform the task of analyzing cast iron samples visually. Visual classification thus still plays a major role in quality assurance especially for small- and medium-sized foundries, although several systems for digital image analysis are available.

Furthermore, the procedure for the individual steps of microstructure evaluation was surveyed. Next to various microscopes and camera systems, different parameter settings during image acquisition are chosen. Concerning the question "What resolution do you use?", different types of answer were recorded: Half of the participant mentioned resolution with pixel number between 1.3 and 5.5 MP (majority naming 3.1 or $5.1 \mathrm{MP}$ ), whereas nearly a quarter out of 33 given answers mentioned the magnification 
instead. Furthermore, two participants named the calibration factor of the value 0.35 and $0.63 \mu \mathrm{m} / \mathrm{Pixel}$, respectively, whereas the rest gave no clear answer. Although imprecisely asked, the role of the resolution or calibration factor and difference to the magnification is not clear for all analysts, which means that neglecting a constant resolution does result in digital graphite analysis results, which are more difficult to compare.

Answering the question "Can you briefly describe your experiences with visual evaluation?", the participants stated that visual evaluation is mostly used only for controlling and correcting the results of the digital image analysis and in case of critical parts at the edge between acceptable and not acceptable microstructure. Furthermore, it was pointed out by the users that non-classified graphite shapes are hard to handle, since there is no clear instructions how they should be assigned. Nevertheless, the visual classification and nodularity determination are widely accepted by the customers.

\section{Digital Evaluation of Graphite Morphologies}

Concerning digital image analysis of cast iron materials, almost all commercially available image analysis systems are in use, although the system AMGuss $^{16}$ (dhs cast iron analyzer ${ }^{17}$ ), developed particularly for cast iron, is most frequently present among the participants. Concerning other universal image analysis software, the participants demand a stricter guide and less options to interfere in the analyzing process to ensure a reproducible measurement. Furthermore, a method to calibrate and control the digital image analysis is missing and thus requiring an experienced operator to check the results instead.

Regarding the question "Particles of which graphite classes would you describe as 'nodules' and add to the nodule count and nodularity?", different weightings (f: weighting factor) were named:

- $38 \%$ voted for "VI $\mathrm{VISO}_{\mathrm{ISO}} \mathrm{f} \cdot \mathrm{V}_{\text {ISO }}$ "

- $35 \%$ voted for "VI ISO $+\mathrm{V}_{\text {ISO }}$ "

- $8 \%$ varied between "VI ISO $+\mathrm{V}_{\text {ISO" }}$ and "VI $\mathrm{ISO}_{\mathrm{ISO}} \mathrm{f} \cdot \mathrm{V}_{\text {ISO }}$ "

- $11 \%$ voted just "VI ISO"

- Shape IV $_{\text {ISO }}$ was considered as partly to be weighted as nodules in a few cases $(8 \%)$

Regarding unclassified graphite morphologies like exploded, chunky or spiky graphite, the need to identify and quantify these was stressed by the survey participants.
Table 2. Assignment of Particle No. 1 from Figure 4

\begin{tabular}{lc}
\hline Assignment & Votes (\%) \\
\hline$V_{\text {ISO }}$ & 24 \\
IISO $_{\text {ISO }}$ & 56 \\
IVI $_{\text {IIISO }}$ & 2 \\
IIISO/spiky graphite $_{\text {ISO }}$ & 0 \\
Chunky graphite & 0 \\
Exploded graphite & 0 \\
Other & 0 \\
\hline
\end{tabular}

\section{Visual Classification of Individual Graphite Particles}

For each particle, the different assignments (graphite classes, degenerated graphite form or other) were counted. For example, particle no. 1 from Figure 4 was assigned by absolute majority as form $\mathrm{V}_{\text {ISO }}$, but was named by a distinctive percentage as $\mathrm{VI}_{\mathrm{ISO}}$ or exploded graphite (cf. Table 2).

\section{Established Graphite Classes}

The particles which had the majority votes for the EN ISO 945-1 classes were identified and in each case summarized as

- $\quad$ high conformity of the participants with a majority more than $75 \%$ for one class or

- acceptable conformity with a majority of 50-75\%.

Figure 5 presents the summarized sets of visually assigned graphite particles. Predominantly $\mathrm{VI}_{\mathrm{ISO}}$ assigned particles (Figure 5a) appear round, whereas partially $\mathrm{VI}_{\text {ISO }}$ assigned particles (Figure 5b) are highly convex, but do not present a round surface. Predominantly $\mathrm{V}_{\text {ISO }}$ assigned particles (Figure 5c) can be described as having a compact and convex shape with less round boundary, whereas partially assigned $\mathrm{V}_{\text {ISO }}$ particles (Figure $5 \mathrm{~d}$ ) are mostly not convex. Extracted graphite particles from malleable cast iron (Figure 5e) are also not convex, but appear in contrast to $\mathrm{V}_{\text {ISO }}$ assigned particles less compacted and more ragged. Although the focus was not on compacted graphite morphologies, it can be stated that predominantly III $_{\text {ISO }}$ assigned particles (Figure 5f) are vermicular, whereas

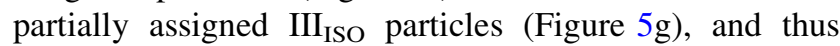
critical particles, are thinner or smaller. IV $\mathrm{V}_{\text {ISO }}$ was also an answering option for the test particles, but votes for IV $_{\text {ISO }}$ barely reached a simple majority, mostly $0-30 \%$ consent. 

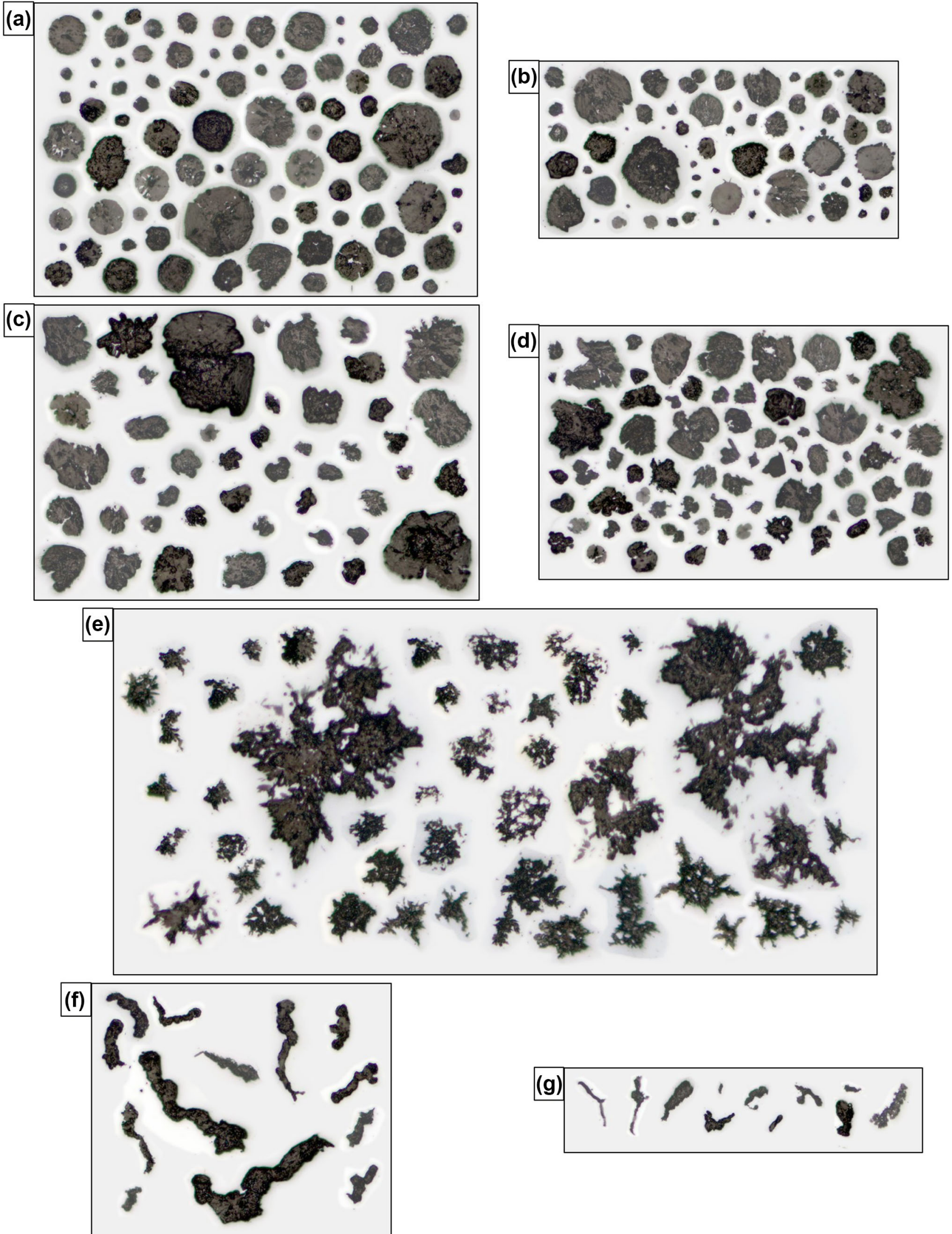

Figure 5. Summarized assignment: (a) $>75 \%$ voted for $V_{I S O}$, (b) $50-75 \%$ voted for $V I_{I S O}$, (c) $>75 \%$ voted for $V_{\text {ISO }}$, (d) $50-75 \%$ voted for $V_{I s o}$, (e) extracted IV Iso particles from malleable cast iron, (f) $>75 \%$ voted for IIIISO, (g) $50-75 \%$ voted for IIIIso. 


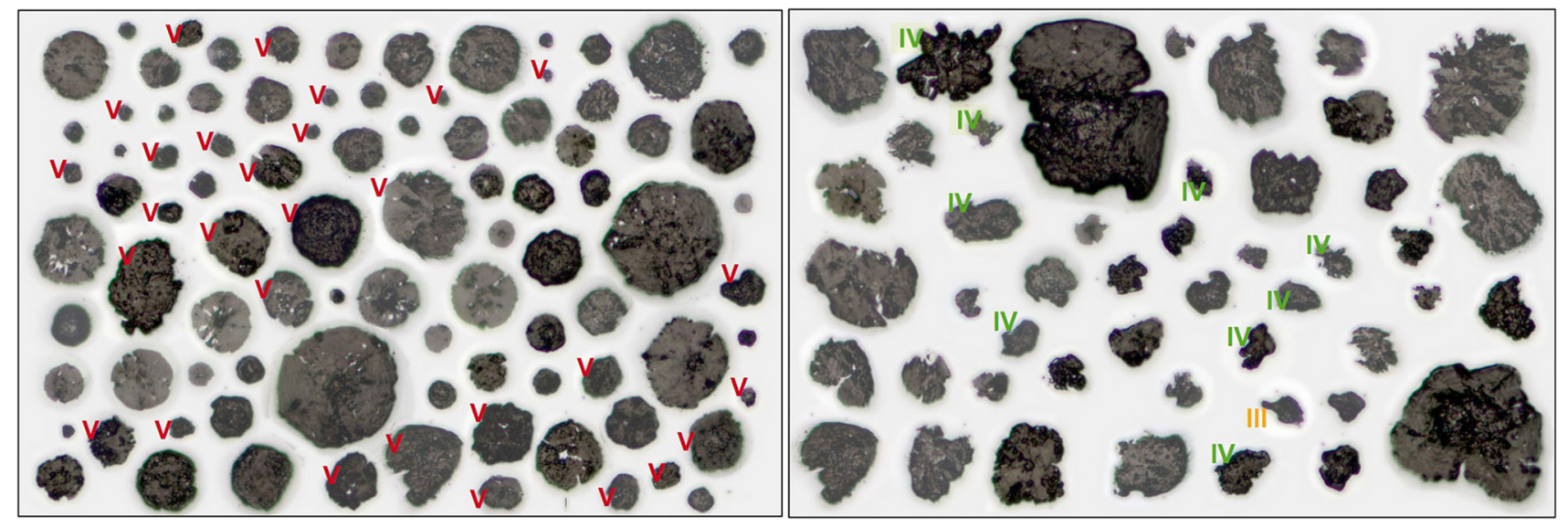

Figure 6. Left: in the visually assigned set of $\mathrm{VI}_{\text {ISO }}$ graphite particles, differently automated assigned particles are marked. Right: in the visually assigned set of $V_{\text {Iso }}$ graphite particles, differently automated assigned particles are marked.

Thus, no summarized data set was extracted for visually assigned $\mathrm{IV}_{\text {ISO }}$ particles.

When using roundness as a state-of-the-art classification approach with lower limit of 0.8 and 0.6 for $\mathrm{VI}_{\text {ISO }}$ and $\mathrm{V}_{\text {ISO }}$ classification, a concordance of $70 \%$ for " $>75 \%$ visually assigned $\mathrm{VI}_{\text {ISO }}$ particles" and a concordance of $77 \%$ for "VISO particles" are achieved. For $50-75 \%$ visual agreements, these values are $20 \%\left(\mathrm{VI}_{\mathrm{ISO}}\right)$ and $64 \%\left(\mathrm{~V}_{\text {ISO }}\right)$, respectively. Figure 6 shows the deviating assignments for the ">75\%" graphite particle sets.

Figure 7 shows roundness values for the summarized sets of assigned particles (cf. Figure 5). The assignments to nodules, based on the parameter roundness, differ from the visual classification of individual particles. Predominantly $\mathrm{VI}_{\mathrm{ISO}}$ assigned particles have a roundness down to 0.7 (one lower outlier), and partly assigned $\mathrm{VI}_{\mathrm{ISO}}$ particles have a roundness down to 0.6 . The predominantly $\mathrm{V}_{\text {ISO }}$ assigned particles lay well in the range of $0.6-0.8$, whereas partly assigned $\mathrm{IV}_{\text {ISo }}$ particles feature roundness values down to 0.45 . Nevertheless, these $\mathrm{VI}_{\text {ISO }}$ and $\mathrm{V}_{\text {ISO }}$ assigned particles sets have an overlap in the range of 0.6-0.8. Extracted graphite particles from malleable cast iron show roundness values between 0.33 and 0.7 and thus overlapping with

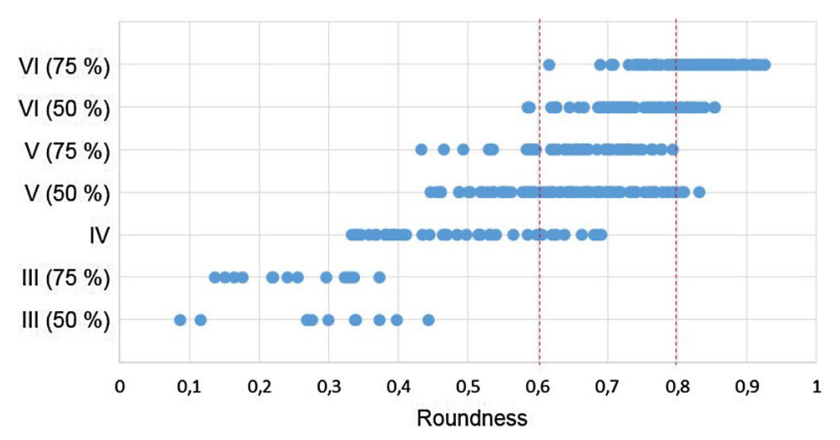

Figure 7. Roundness parameters determined by image analysis for the visually assigned graphite particles. nodules partly. The investigated III $_{\text {ISO }}$ assigned particles lie in the roundness range between 0.1 and 0.45 . None of the measured particles have a roundness above 0.94 , which is caused by the pixel measurement itself.

When combining more than one shape parameter like solidity, sphericity and the ratio of convex perimeter to perimeter (cf. Figure 8a, b), less overlapping ranges can be observed. This also includes the separation of $\mathrm{VI}_{\mathrm{ISO}}$ and $\mathrm{V}_{\text {ISO }}$ assigned particles (cf. Figure $8 \mathrm{c}, \mathrm{d}$ ).

\section{Exploded Graphite}

Next to the established classes, other graphite morphologies were investigated. Figure 9 shows an assembly of graphite particles with enclosed ferrite matrix toward different scales of exploded graphite. Figure 10 shows the participants assignment of some of these particles. Whereas E.03 is mainly considered as a nodule, particles E.04-E.08 are ambiguously assigned, including $\mathrm{IV}_{\mathrm{ISO}}$, which is defined as graphite particles of malleable cast iron. An example of a predominantly assigned exploded particle is E.09, although also more than a quarter of participants assigned this as $\mathrm{IV}_{\mathrm{ISO}}$. Different opinions regarding drawing the line between nodules and exploded graphite particles exists as EN ISO 945-1 gives no classification of exploded graphite particles.

\section{Other (Degenerated) Graphite Morphologies}

For a certain part of example particles, unclassified degenerated graphite morphologies were favored or no absolute majority among the participants could be established. Figure 11 depicts such particles which feature a plurality for a certain graphite group. Figure 11a shows a lamellar-like particle in a ductile iron sample. (Different 
(a)

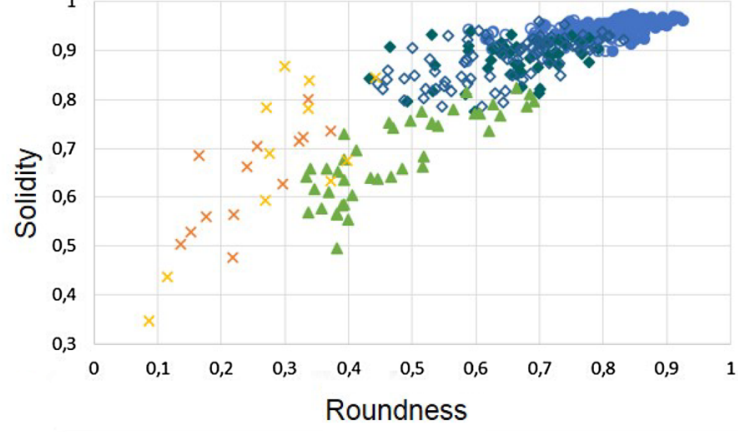

(c)

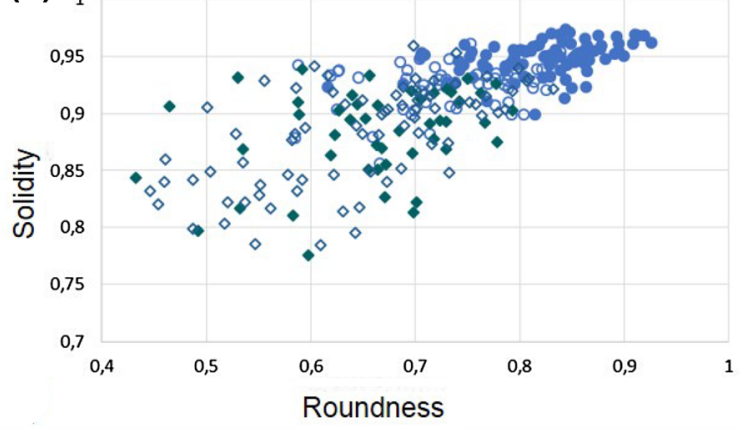

(b)

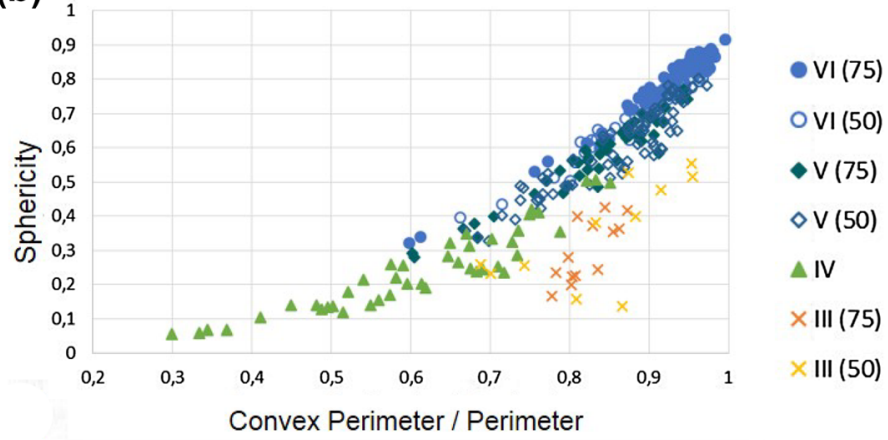

(d)

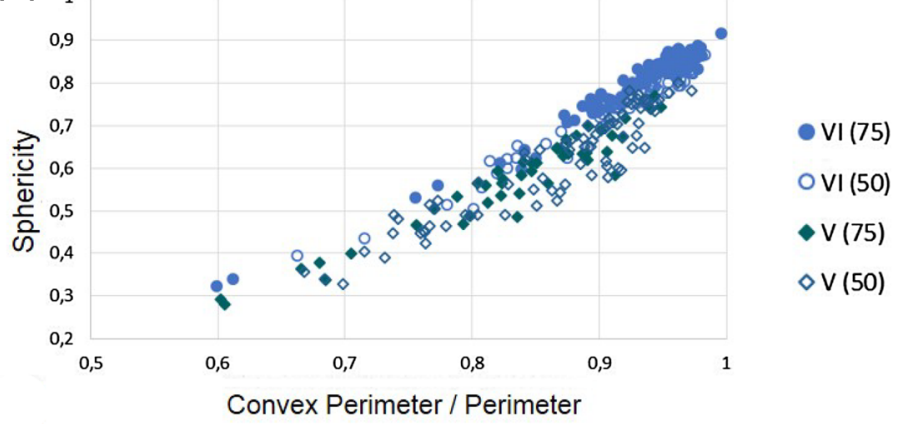

Figure 8. (a) and (b) Shape parameter combinations for the visually assigned particles $V_{I S O}$. $V_{I S O}$ and IIIISO with 50 and $75 \%$ minimum majority as well as graphite particles from malleable cast iron (IVISO), (c) and (d) enhanced plots of $V_{I S O}$ and $V_{I S O}$ particles.
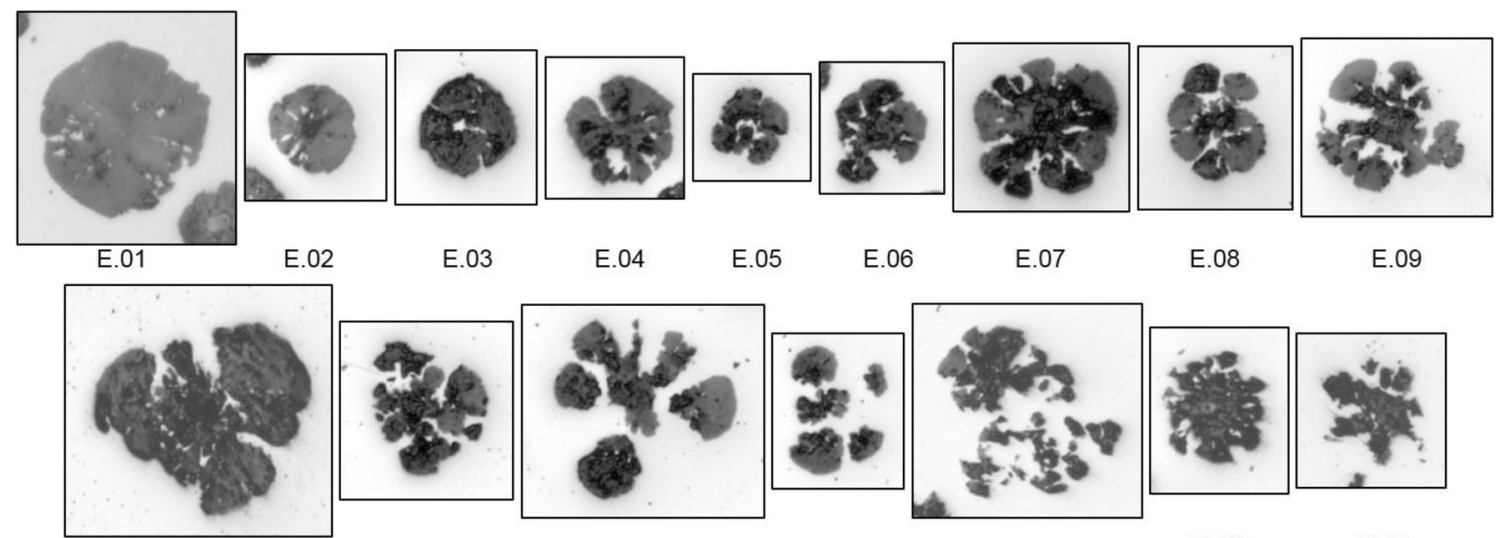

E.02 E.03

E.04

E.05

E.06

E.07

E.08

E.09

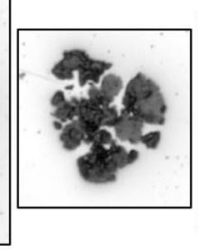

E.11

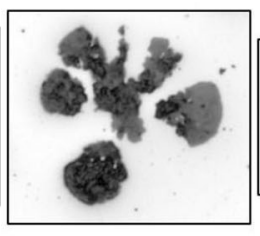

E.12

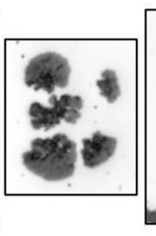

E.13

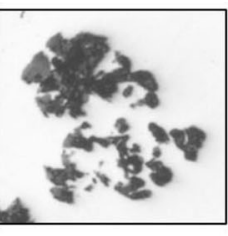

E.14

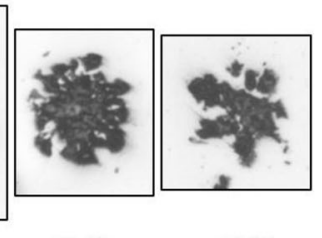

E. 15
E.16

Figure 9. Variation of round and exploded graphite particles. (Note: E.04 is particle no. 1 in Figure 4).

degenerated graphites were present in this sample.) Figure $11 \mathrm{~b}$ shows spiky graphite particles. Figure $11 \mathrm{c}$ shows small, slightly elongated but compacted graphite (often assigned as $\left.\mathrm{III}_{\mathrm{ISO}}\right)$. Figure $11 \mathrm{~d}$ shows individual particles which were assigned to $\mathrm{IV}_{\mathrm{ISO}}$, although they do not originate from malleable cast iron samples. Nevertheless, these particles have no equivalent within the classification approaches (cf. Figure 1). Figure 11e shows those particles with very variant assignments.

\section{Visual Classification of Graphite Areas}

The appearances of graphite phases in 2D sections may differ from the 3D structure of graphite, meaning that neighboring particles may belong to a larger 3D network (like chunky graphite or branches of vermicular graphite). Experienced metallographers may (re-)cognize these kinds of structures, but an algorithm needs implementation on how to categorize these geometrical data. Figure 12 shows some of the questioned areas (like the blue rectangles in 


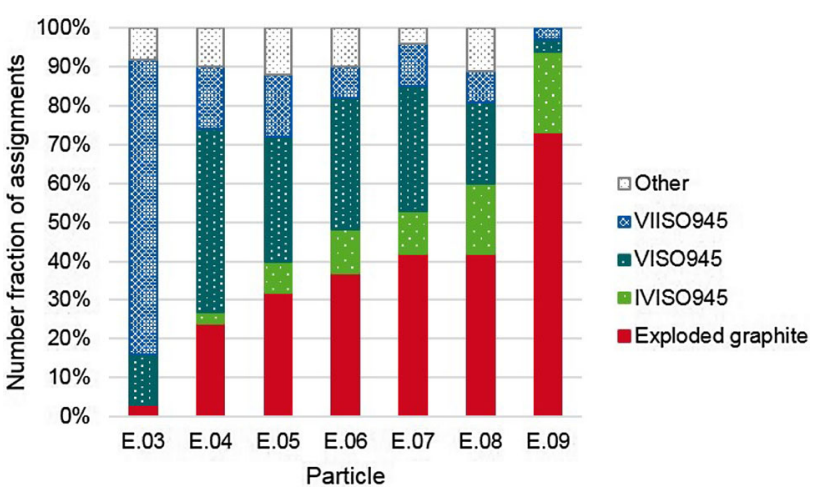

Figure 10. Visual assignment of some the in Figure 9 presented particles.

Figure 4), in order to obtain a reference set of sectioned 3D graphite structures.

\section{Visual Analysis of Nodularity}

In the round robin test, the nodularity was to determine between 95 and $25 \%$ and the option "below 25\%" was set to $25 \%$ for further analysis. Figure 13 shows the comparison between the averaged visually determined nodularity and the digital measured nodularity. The visual nodularity exhibits large variation among the participants. Except for some outliers at lower visual nodularity values, the average visual nodularity is in accordance with the digitally measured nodularity.

Figure 14 shows micrographs where the visually estimated nodularity deviates around the average of $62-64 \%$ with a standard deviation of $20 \%$. Whereas in the first image (Figure 14a) small particles make it hard to determine the graphite shapes since smaller particles appear unsharp and thus blurred and roundly, Figure 14b contains graphite particles which do not have equivalents in EN ISO 945-1 (cf. Figure 1) [but are partly in accordance with $\mathrm{II}_{\mathrm{ASTM}}$ ], making it inconclusive whether these particles should be considered round, thus resulting in variant nodularity assignments. Figure 14c also shows variant non-round and round particles. Considering common reference images, ${ }^{7,18,19}$ decreasing nodularity values are often represented by an increased compacted graphite content and not by other degenerated graphite morphologies. So in the presence of other graphite anomalies, no suitable reference charts exist.

(a)

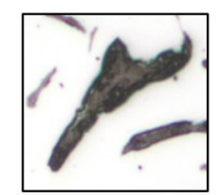

(b)
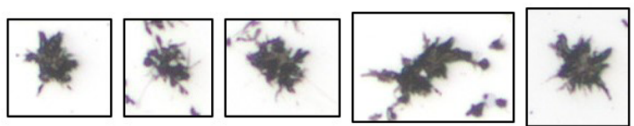

(c)
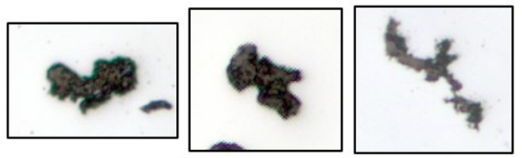

(d)
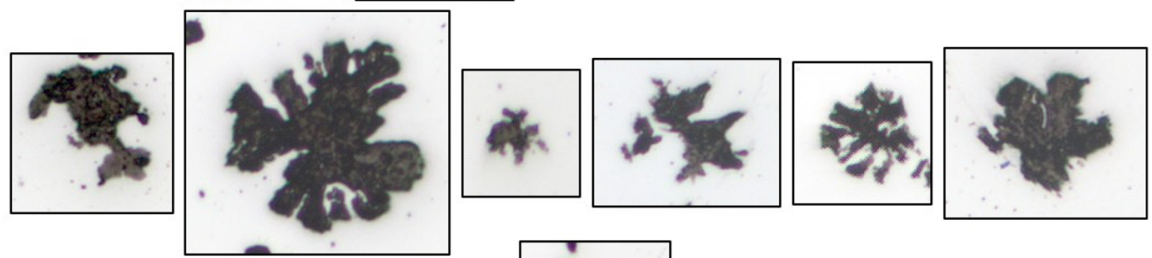

(e)
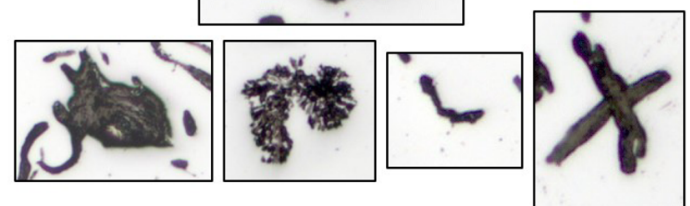

Figure 11. Ambiguous assigned graphite particles but with a tendency to $I_{\text {Iso }}$ (row a), (b) IIIso (row b), IIIIso (row c), IVIso (row d) although it does not origin from malleable cast iron and particles with no tendency toward any class or collective (row e). 
(a)
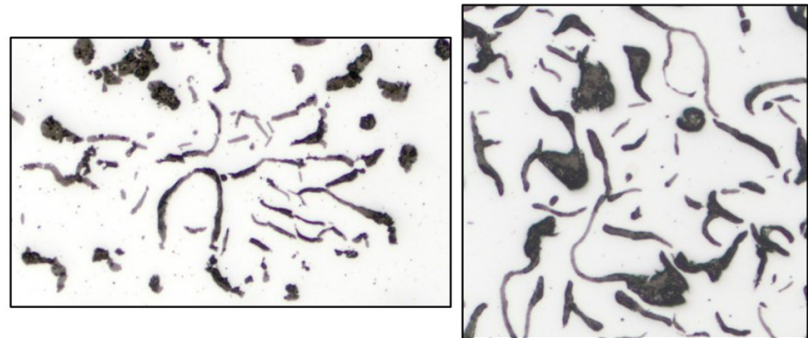

(b)
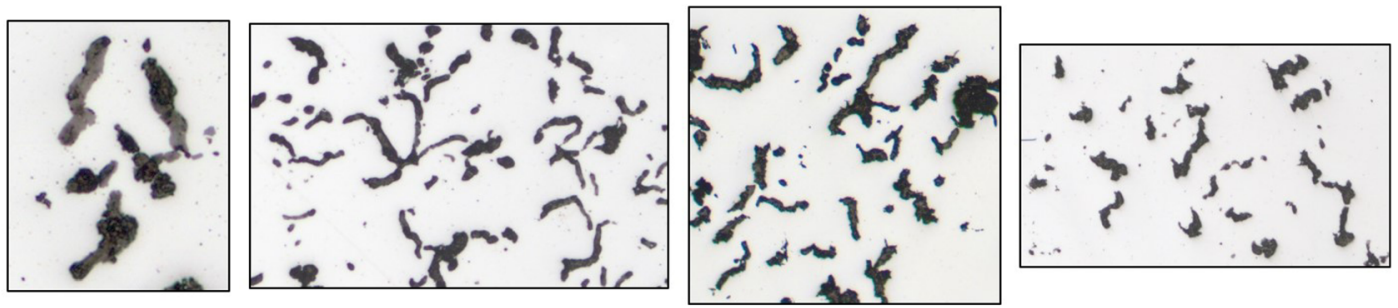

(c)
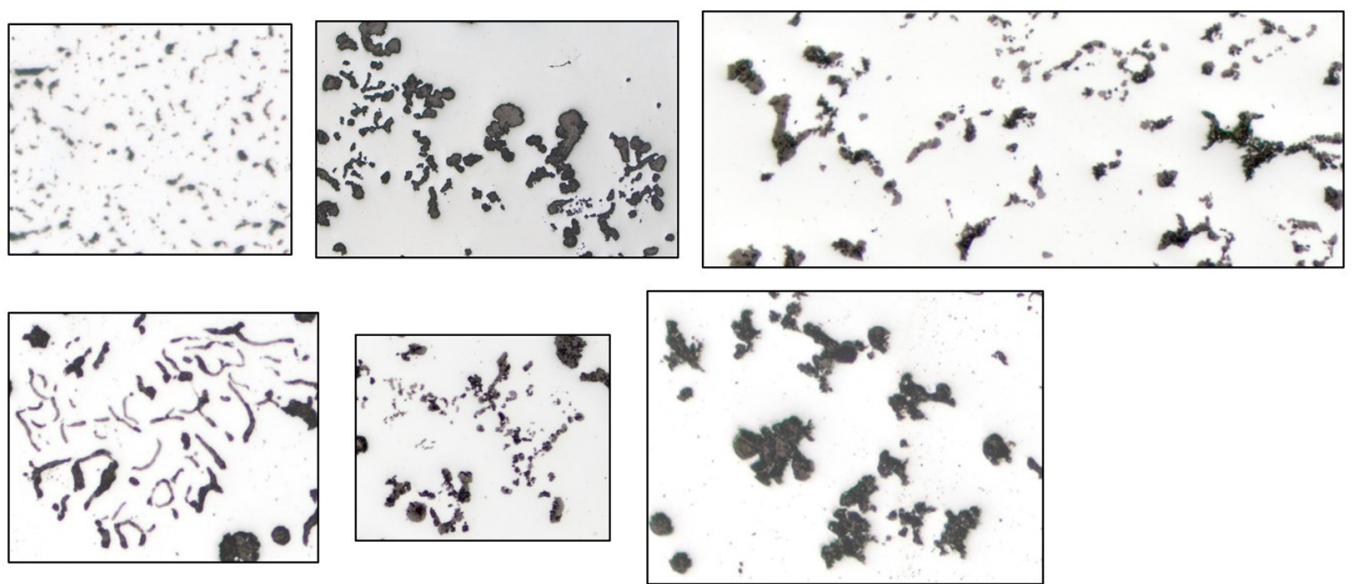

Figure 12. Different graphite areas which were majorly assigned to $I_{I s o}$ (row a), IIIIso (row b), chunky graphite (row c) or unclassified graphite (row d).

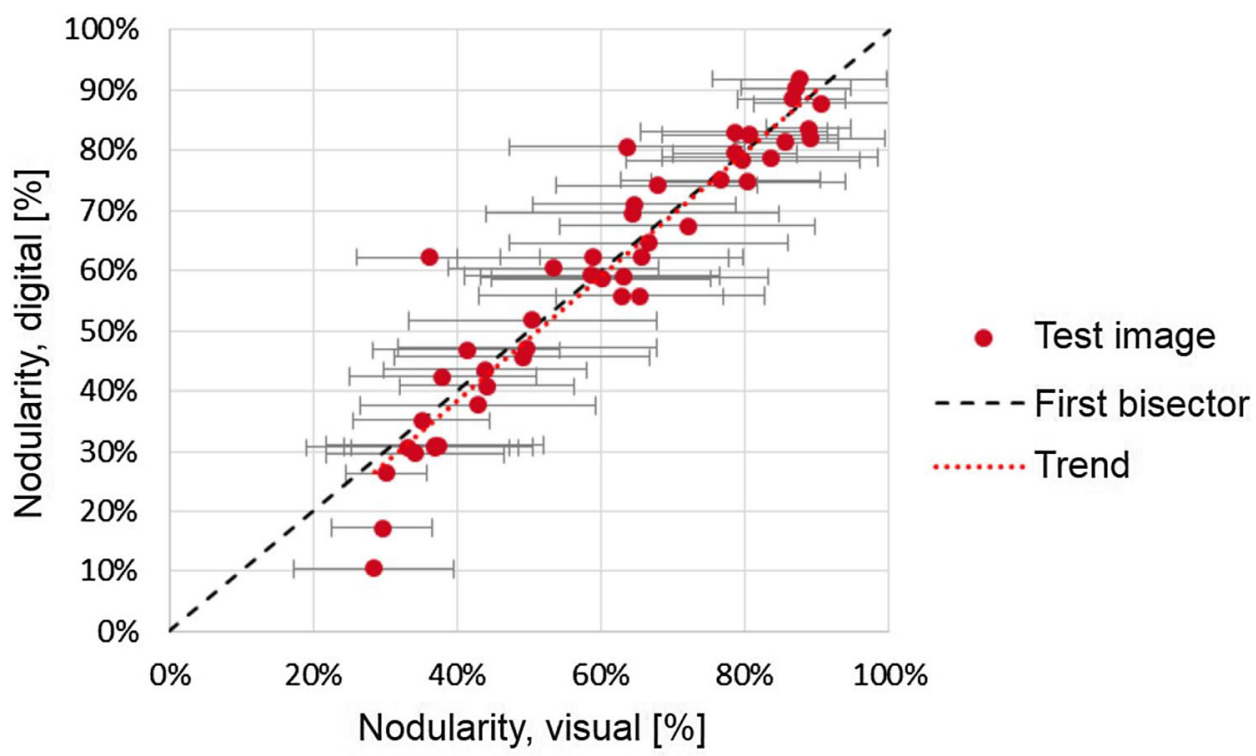

Figure 13. Digitally measured nodularity versus visually determined nodularity of 52 test images. 


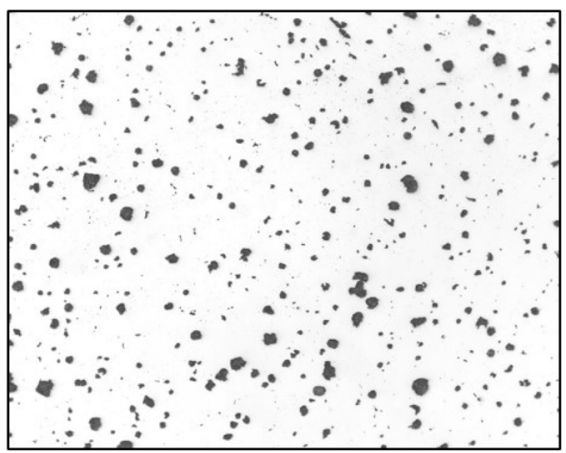

(a)

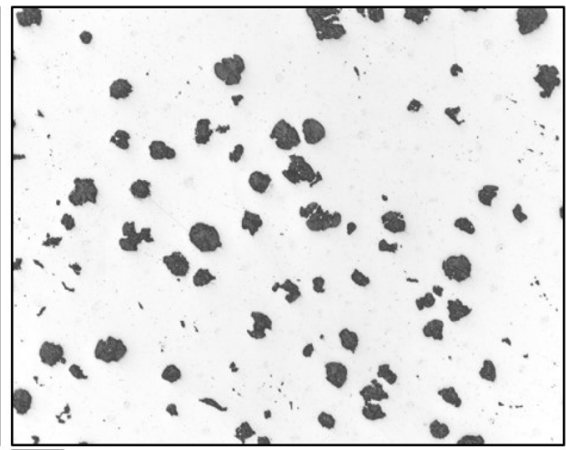

(b)

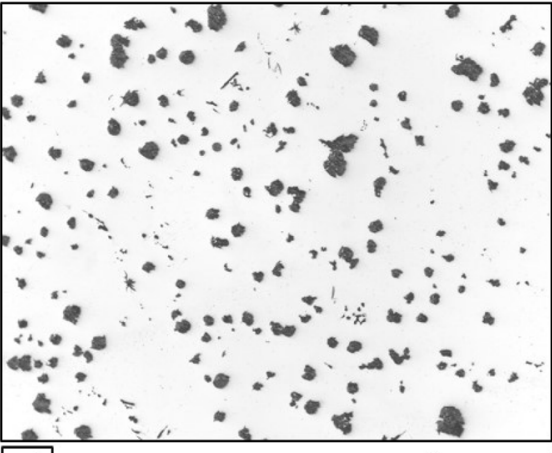

(c)

$200 \mu \mathrm{m}$

Figure 14. Images with average visual nodularity of $62-64 \%$ and high standard deviation among the participants.

\section{Discussion}

\section{Variations of Visual Classification}

\section{Nodules}

Comparing the summarized sets of visually assigned nodules (Figure 5a-d) with the reference tables (Figure 1), significant difference is obvious. Whereas the predominantly $\mathrm{VI}_{\mathrm{ISO}}$ assigned particles are in good accordance with $\mathrm{VI}_{\text {ISO }}$ schematics (and $\mathrm{I}_{\mathrm{ASTM}}$ ), the partially $\mathrm{VI}_{\text {ISO }}$ assigned particles do not have an equivalent within the reference table of EN ISO 945-1 (but are similar to $\mathrm{II}_{\mathrm{ASTM}}$ ). The predominantly $\mathrm{V}_{\text {ISO }}$ assigned particles are less ragged than the $\mathrm{V}_{\text {ISO }}$ schematics, but also similar to $\mathrm{II}_{\mathrm{ASTM}}$. The partially $\mathrm{VI}_{\mathrm{ISO}}$ assigned particles do not have an equivalent in the reference tables. Overall, the study of individual particles shows that the diversity of graphite nodules is greater than indicated in the reference tables, and thus an extension of shown particles beyond the state of sporadic sample images is necessary in order to enable unambiguous assignment.

\section{Individual Non-round Particles}

The overall opinion of the participants was to consider graphite shapes $\mathrm{VI}_{\text {ISO }}$ and $\mathrm{V}_{\text {ISO }}$ as nodules. With $\mathrm{IV}_{\text {ISO }}$ as graphite particles of malleable cast iron, III ISO $_{\text {as com- }}$ pacted and elongated particles as well as $\mathrm{II}_{\mathrm{ISO}}$ as occasional degeneration caused by trace elements, other non-round graphite particles cannot be classified. Due to this lack of a standard, solid particles with a non-round manner as well as exploded graphite particles, for which a class is also missing in the EN ISO 945-1 reference approach, are often differently assigned to $\mathrm{IV}_{\text {ISO }}, \mathrm{V}_{\text {ISO }}$ or left unassigned. A clear distinction between graphite nodules and non-round single particles is necessary, whereby the visually assigned $\mathrm{V}_{\text {ISO }}$ particles (Figure $5 \mathrm{c}$, d) can serve as a suggestion, taking into account that consent for the partially $\mathrm{V}_{\text {ISO }}$ assigned particles (Figure 5c) was just between 50 and $75 \%$, thus calling for further discussions.
Based on this different interpretation of the reference charts, no unified approach has been developed yet. This is an obstacle for shape parameter evaluation and thus of also the algorithm implementation. An extension of graphite classes as well as a clear definition for these classes is recommended.

\section{Shape Parameters for Automatic Classification}

The assigned particles were set in correlation with their shape parameters. One parameter itself, like the often used roundness, is not suitable to distinguish nodules from other single particles. Additionally, a differentiation in $\mathrm{V}_{\text {ISO }}$ and $\mathrm{VI}_{\text {ISO }}$ is not possible by roundness. This is because the particle is just compared to a circle, but the actual shape is not described by a single parameter (cf. Figure 2). Graphite particles need to be evaluated according to different properties like similar shapes (e.g., convex shape: convexity), elongation (FeretRatio), branching (compactness) and inner (ferritic) structure (solidity) next to roundness, since the graphite morphologies are manifold.

Indications for characteristic shape parameters and limit ranges with regard to shape classification were identified. Shape parameters such as sphericity and solidity should be taken into account. Since the different graphite classes can be characterized by different shape parameters, a stepwise and hierarchical classification algorithm (cf. Figure 15) is proposed, which uses different shape parameters depending on the eligible form classes. This approach will be evaluated in an upcoming round robin test.

\section{Conclusion}

Clearly assigned (according to EN ISO 945-1) and ambivalent graphite particles were identified by asking for subjective (visual) classification of selected particles in a round robin test in the course of a German research and development project. A representative data set for the different form classes VI ("round"), V ("reasonably 


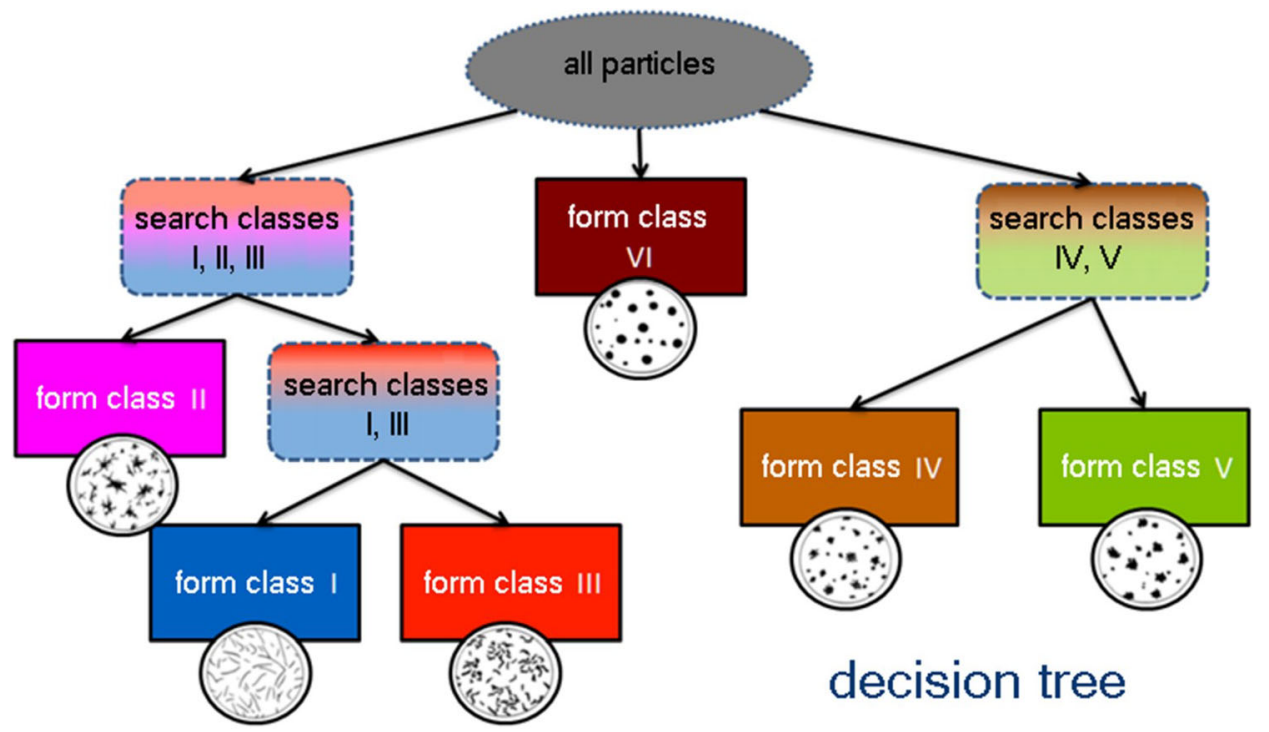

Figure 15. Hierarchical classification approach [20].

round"), IV (temper carbon) was compiled, which serves as a unified basis for further investigations.

Different reasons for a varying visual analysis were evaluated. These can be stated as a substantial cause for the deviating digital analysis, since there is no common basis on how to implement the classification approach into an algorithm.

The graphite morphologies present in ductile iron (and cast iron materials in general) can exhibit a wide range of variations and cannot be assigned to the stylized graphite shapes in existing reference charts of international standards using only the parameter roundness. To solve the graphite classification task, an adapted hierarchical classification approach for the classes of EN ISO 945-1 and suitable shape parameters are suggested and might be adaptable to ASTM A247 and E2567.

Furthermore, it was shown that the current classification standards ${ }^{8,9}$ do not cover the full variety of graphite morphologies in ductile iron. It is strongly suggested to extend the reference charts with other non-round graphite morphologies, which can be present at the same time as the respective desired graphite morphology. Those undesired graphite degenerations should also be depicted and defined in order to enable analysts to classify graphite particles without a doubt.

\section{Acknowledgements}

Open Access funding provided by Projekt DEAL. The presented results are derived from IGF Project 19363 N of the "FVG Research Association of the Foundry Industry" which was funded within the scope of the joint collaborative program "IGF" by the Federal
Ministry for Economic Affairs and Energy, following a decision of the German Bundestag. The authors would also like to thank the participants of the interlaboratory study.

Open Access This article is licensed under a Creative Commons Attribution 4.0 International License, which permits use, sharing, adaptation, distribution and reproduction in any medium or format, as long as you give appropriate credit to the original author(s) and the source, provide a link to the Creative Commons licence, and indicate if changes were made. The images or other third party material in this article are included in the article's Creative Commons licence, unless indicated otherwise in a credit line to the material. If material is not included in the article's Creative Commons licence and your intended use is not permitted by statutory regulation or exceeds the permitted use, you will need to obtain permission directly from the copyright holder. To view a copy of this licence, visit http://creativecommons. org/licenses/by/4.0/.

\section{REFERENCES}

1. EN 1563:2011: Spheroidal graphite cast irons

2. S.I. Karsay, Gusseisen mit Kugelgraphit, Grundlagen - Technologien (QIT Fer et Titane Inc., Quebec, 1992)

3. J. Ohser, K. Sandau, W. Stets, W. Gerber, Image analytical characterization of graphite in grey cast iron and classification of lamellar arrangement. Prakt. Metallogr. 40(9), 454-473 (2003)

4. S. Grenier, C. Labrecque, A. Bhattacharjee, R. Gundlach, B. Kroka, M. Riabov, Inter-laboratory study of nodularity and nodule count of ductile iron by image analysis. Inter Metalcast 8, 51 (2014). https://doi.org/ 10.1007/BF03355582

5. V. Smolej, Image analysis for materials testing, industrial heating, p. 55-57 (2001)

6. IFEP, Germany, Eignungsprüfung Metallographie Bildauswerteverfahren MET-OI Nr. 1113 (2011) 
7. ISO/DIS 945-4:2016(E) working draft: microstructure of cast irons-part 4: test method for determining nodularity in spheroidal graphite cast irons. Working Draft (2016)

8. EN ISO 945-1: Microstructure of cast irons-part 1: graphite classification by visual analysis (ISO 945-1:2017)

9. ASTM A247 - 16a Standard test method for evaluating the microstructure of graphite in iron castings. ASTM International, West Conshohocken, PA. www. astm.org (2016)

10. ASTM E2567 - 16a: Standard test method for determining nodularity and nodule count in ductile iron using image analysis. ASTM International, West Conshohocken, PA. www.astm.org (2016)

11. ISO 16112. Compacted (vermicular) graphite cast irons-classification. ISO, (2006)

12. A. Velichko, Quantitative 3D characterization of graphite morphologies in cast iron using fib microstructure tomography. Dissertation, Saarbrücken, Germany (2008)

13. M. Shirani, G. Härkegård, Large scale axial fatigue testing of ductile cast iron for heavy section wind turbine components. Eng. Fail. Anal. Sep. 18(6), 1496-1510 (2011)

14. BDG, Internal Report: Current State of ISO 945-4 WD, Fachausschuss Eisenguss, 2016

15. soSci - der online Fragebogen. www.soscisurvey.de

16. http://www.gfai.de/fileadmin/user_upload/GFaI-Pro duktblatt_AMGuss_de.pdf. Accessed 16th May 2018

17. https://www.dhssolution.com/fileadmin/sites/dhssolu tion.com/website/media/produkte/datenblaetter_Soft ware/Analyse_EN/dhssolution_dhs-image-data-base_ datasheet_modul_cast-iron-analysis_12-2015.pdf.

Accessed 16th May 2018

18. ELKEM, Ductile Iron Structures and Defects, Poster, provided by Elkem

19. SinterCast, Compacted Graphite Iron, Poster, provided by SinterCast (2015)

20. Hierarchical classification approach, personally provided by U. Sonntag, GFaI, Berlin, Germany, (2018)

Publisher's Note Springer Nature remains neutral with regard to jurisdictional claims in published maps and institutional affiliations. 